\title{
Bronchiectasis exacerbations: The role of atypical bacteria and respiratory syncytial virus
}

\author{
Eugenios I Metaxas MD MSc${ }^{1}$, Evangelos Balis MD PhD¹, Joseph Papaparaskevas MD PhD², \\ Nicholas E Spanakis MD PhD², Georgios Tatsis MD PhD ${ }^{1}$, Athanasios Tsakris MD PhD²
}

EI Metaxas, E Balis, J Papaparaskevas, NE Spanakis, G Tatsis, A Tsakris. Bronchiectasis exacerbations: The role of atypical bacteria and respiratory syncytial virus. Can Respir J 2015;22(3):163-166.

BACKGROUND: Aside from the known role of common bacteria, there is a paucity of data regarding the possible role of atypical bacteria and viruses in exacerbations of non-cystic fibrosis bronchiectasis.

OBJECTIVE: To explore the possible role of atypical bacteria (namely, Mycoplasma pneumoniae and Chlamydophila pneumoniae) and respiratory syncytial virus (RSV) as causative agents of bronchiectasis exacerbations. METHODS: A cohort of 33 patients was studied over a two-year period (one year follow-up for each patient). Polymerase chain reaction for the detection of M pneumoniae, C pneumoniae and RSV in bronchoalveolar lavage samples were performed during all visits. Antibody titres (immunoglobulin [Ig]M and $\operatorname{IgG}$ ) against the aforementioned pathogens were also measured. In addition, cultures for common bacteria and mycobacteria were performed from the bronchoalveolar lavage samples.

RESULTS: Fifteen patients experienced a total of 19 exacerbations during the study period. Although RSV was detected by polymerase chain reaction during stable visits in four patients, it was never detected during an exacerbation. M pneumoniae and $\mathrm{C}$ pneumoniae were never detected at stable visits or during exacerbations. IgM antibody titres for these three pathogens were negative in all patient visits.

CONCLUSIONS: Atypical pathogens and RSV did not appear to be causative agents of bronchiectasis exacerbations.

Key Words: Atypical bacteria; Bronchiectasis; Exacerbations; Respiratory syncytial virus

\section{Les exacerbations de la bronchectasie : le rôle des bactéries atypiques et du virus respiratoire syncytial}

HISTORIQUE : On connaît le rôle des bactéries courantes dans les exacerbations des bronchectasies non attribuables à la fibrose kystique, mais on possède peu de données sur celui des bactéries et des virus atypiques. OBJECTIF : Explorer la possibilité que des bactéries atypiques (le Mycoplasma pneumoniae et la Chlamydophila pneumoniae) et le virus respiratoire syncytial (VRS) soient responsables d'exacerbations de la bronchectasie.

MÉTHODOLOGIE : Une cohorte de 33 patients a fait l'objet d'une étude de deux ans (suivi de chaque patient pendant un an). À chaque rendez-vous, les chercheurs ont effectué une amplification en chaîne de la polymérase (PCR) de prélèvements de lavage broncho-alvéolaire pour déceler le M pneumoniae, la C pneumoniae et le VRS. Ils ont mesuré les titres d'anticorps (immunoglobuline $[\mathrm{Ig}] \mathrm{M}$ et $\operatorname{IgG}$ ) contre ces pathogènes. Enfin, ils ont procédé à des cultures de bactéries et mycobactéries courantes dans les prélèvements des lavages broncho-alvéolaires.

RÉSULTATS : Quinze patients ont subi un total de 19 exacerbations pendant la période de l'étude. Même si le VRS a été décelé par PCR lors du rendez-vous de quatre patients stables, il ne l'a jamais été pendant une exacerbation. On n'a jamais décelé le M pneumoniae ou la C pneumoniae chez les patients stables ou en exacerbation. Les titres d'anticorps de l'IgM de ces trois pathogènes étaient négatifs lors de tous les rendez-vous. CONCLUSIONS : Les pathogènes atypiques et le VRS ne semblaient pas responsables des exacerbations de la bronchectasie.
$\mathrm{B}$ ronchiectasis is a chronic respiratory disease involving repeated Binfections and inflammation of both large and small airways. Multiple conditions are associated with the development of bronchiectasis, but all require an infectious insult and additional impairment of drainage, airway obstruction and/or a defect in host defense. The common characteristic of bronchiectasis, which is also considered to be the main pathophysiological mechanism, is the chronic colonization of the lower respiratory tract that leads to secondary inflammatory reactions and progressive lung injury (1), known as the 'vicious cycle' hypothesis (2).

Factors associated with disease progression and deterioration of lung function are chronic colonization by Pseudomonas aeruginosa, severe exacerbations and increased systemic inflammation (3). The main pathogens isolated from $60 \%$ to $90 \%$ of the patients with exacerbations are Haemophilus influenzae and Pseudomonas species. However, there is a lack of data regarding the possible role of viruses and atypical bacteria in bronchiectasis exacerbations.

Given the aformentioned, we endeavoured to examine the role of atypical pathogens (namely, Mycoplasma pneumoniae and Chlamydophila pneumoniae) and respiratory syncytial virus (RSV) as causative agents of bronchiectasis exacerbations.

\section{METHODS}

A two-year, single-centre, observational prospective cohort study was designed and performed in a 900-bed tertiary care general hospital. The study was approved by the Ethics Committees of Evaggelismos General Hospital and the Medical School of National and Kapodistrian University of Athens (Athens, Greece). Eligibility criteria were adults with known or newly diagnosed bronchiectasis. To confirm the presence and the extent of bronchiectasis, high-resolution computed tomography (HRCT) was required for all patients. Exclusion criteria comprised inability to undergo bronchoscopy due to severe heart problems or respiratory failure, and the inability to maintain a personal calendar. Cystic fibrosis $(\mathrm{CF})$ patients were also excluded because they have different epidemiological characteristics $(4,5)$. Candidates were referred to the study team, who informed the patients about the aims and purposes of the study. All patients who were suitable and willing to participate were asked to provide informed written consent.

\section{Definitions}

Exacerbation was defined as the deterioration of at least three respiratory symptoms (cough, increased sputum volume or change in viscosity, sputum purulence with or without increasing wheeze, increased sputum

\footnotetext{
${ }^{1}$ Pulmonology Department, Evaggelismos General Hospital; ${ }^{2}$ Microbiology Department, Medical School, National and Kapodistrian University of Athens, Athens, Greece

Correspondence: Dr Eugenios I Metaxas, Ethnikis Antistaseos 29, Limassol, Cyprus. Telephone 357-99315080, fax 357-25108148, e-mail eumetaxas@yahoo.gr
} 


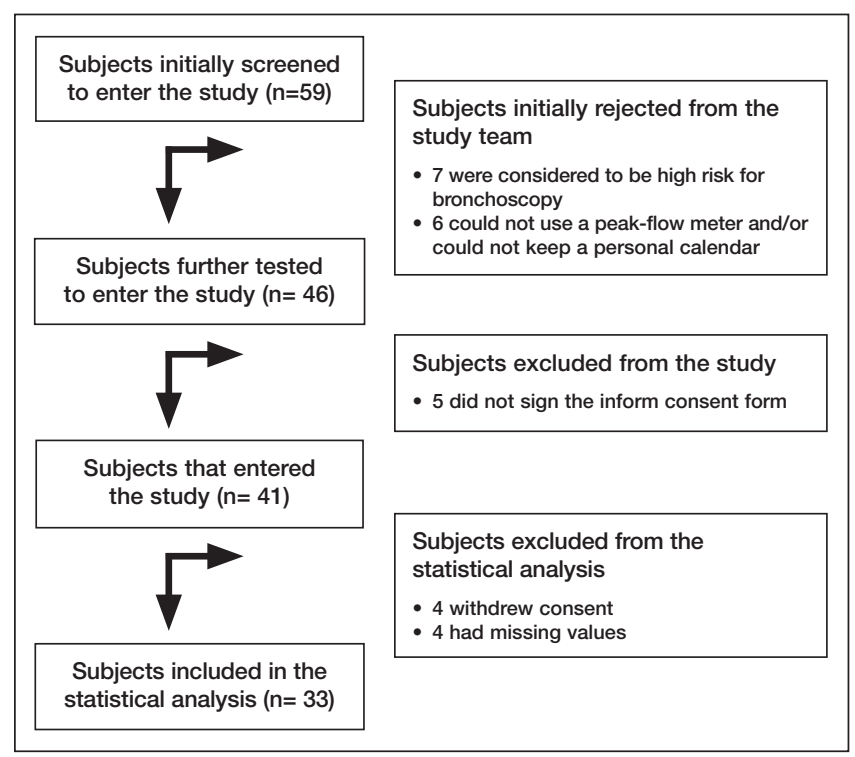

Figure 1) Flow diagram of the bronchiectasis cohort study

production, dyspnea, hemoptysis and chest pain) for $>24 \mathrm{~h}$ and/or systemic complaints, such as fever, and alterations in chest radiograph $(3,6)$. Stable condition was defined as the simultaneous absence of clinical symptoms and elevated inflammation markers. An acute or presumed acute infection from atypical pathogens or RSV was defined as the presence of a positive polymerase chain reaction (PCR) test from bronchoalveolar lavage (BAL) samples with or without immunoglobulin (Ig)M antibodies above cut-off values, or a fourfold increase in IgG antibody titre combined with clinical features (7-9).

\section{Management and follow up}

Subjects were enrolled during a two-year period and were followed for 12 months from enrollment day. The first baseline visit occurred during a stable condition period and, if the patients were in a stable condition, they were followed up every four months. If an exacerbation occurred, patients were monitored during the exacerbation and the next planned visit was omitted. If an exacerbation occurred during the last planned visit, a fifth visit was performed six weeks after the exacerbation. Finally, if a patient did not experience an exacerbation, the last visit was omitted. During the first visit, medical history and epidemiological characteristics were recorded. Patients were given a personal calendar to record their bronchiectasis-related symptoms (eg, dyspnea, sputum production) and a peak-flow meter. On every visit - stable condition or exacerbation - blood samples were obtained and patients were submitted to bronchoscopy and pulmonary function tests.

\section{Collection and process of samples}

During visits, blood samples were obtained to measure inflammation parameters such as white blood cell count, C-reactive protein level, and antibodies (IgM and IgG) against $\mathrm{C}$ pneumoniae, $M$ pneumoniae and RSV. Subsequent to the initial baseline measurement of antibodies, a second baseline measurement, taken three weeks later, was performed to identify any latent or ongoing infections. Antibodies against M pneumoniae, C pneumoniae and RSV were detected using immunofluorescence assay (Focus, USA), microimmunofluorescence assay (MRL Diagnostics, USA) and ELISA (Serion, Germany), respectively. BAL samples were obtained during bronchoscopy from the most affected lobe (according to HRCT). Cultures for mycobacteria and quantitative cultures for common pathogens were performed. Bacterial species were classified as potential pathogens or not, as described previously (10). In BAL samples, conventional PCR for M pneumoniae and $\mathrm{C}$ pneumoniae was performed as described previously $(11,12)$.
Real-time PCR was performed using the M pneumoniae, $\mathrm{C}$ pneumoniae and the RSV Real-Time RT-PCR Kits (Obelis SA, 1040, Belgium). Before the study's PCRs tests, positive control tests were performed to confirm test accuracy.

\section{Statistical analysis}

Nonparametric tests and $t$ tests were used to identify differences in measurable parameters between subgroups of the cohort. To identify factors associated with exacerbations, univariate logistic regression models and cross-tabulations were used. Univariate logistic regression and cross-tabulations for nonrepeated measurements were applied including each patient once. All reported $\mathrm{P}$ values are two tailed; the level of significance (ie, alpha value) was 0.05 with a $95 \%$ level of confidence.

\section{RESULTS}

A total of 59 patients with bronchiectasis were screened during recruitment period, of whom 41 were enrolled. Only 33 patients completed the follow-up procedure and were included in the final analysis (Figure 1). During the study, 116 patient visits were occurred. Ninetyseven $(84 \%)$ visits were performed during periods of stable condition, baseline or follow-up and $19(16 \%)$ during exacerbations. Fifteen patients (45\%) experienced at least one exacerbation and four experienced two exacerbations during follow-up; three of these were hospitalized but were eventually discharged. Bronchoscopies were generally well tolerated because high-risk patients were excluded. Only minor adverse events, such as cough and throat irritation, occurred. No deaths were recorded during the study. A summary of the mean values of the inflammation markers are presented in Table 1.

\section{Serology and PCR results}

IgM-specific antibodies against $\mathrm{C}$ pneumoniae and $\mathrm{M}$ pneumoniae were negative in all cases. There was only one patient who had a fourfold increase of the IgG antibodies against $\mathrm{C}$ pneumoniae during the baseline visit. This patient did not exhibit any signs of infection and did not fulfill exacerbation criteria. Regarding RSV, there were no positive IgM samples or any increase in IgG titres. Molecular detection of atypical pathogens and RSV was performed in all 116 samples collected. There was no detection of $\mathrm{C}$ pneumoniae or $\mathrm{M}$ pneumoniae DNA during baseline periods. In contrast, RSV RNA was detected four times during baseline periods (Table 2). All four patients had positive IgG antibodies against RSV. Three of them had a change in IgG titres during the second measurement three weeks later but it was less than fourfold. The same three patients experienced some baseline respiratory symptoms, according to their personal calendars, but did not fulfill the criteria for an exacerbation. All PCR samples during exacerbations were negative for both atypical bacteria and RSV, including two of the patients from whom RSV RNA was isolated during the baseline periods.

\section{Common bacterial pathogens}

Isolation of a microorganism from BAL cultures was achieved in 14 (42\%) different patients in 29 visits (24\%). Eighteen visits were during stable condition and 11 during exacerbations. In some cultures, more than one bacterial species was isolated. The only non-potential pathogenic microorganism isolated was Candida albicans (Table 3). Eleven patients who presented during an exacerbation were treated successfully with antibiotics. Nontuberculous mycobacteria or multiresistant bacteria were not isolated. With regard to exacerbations, nine different patients had a total of 11 positive cultures. Three of them were colonized from the same bacterium that was isolated during the exacerbation: one with Staphylococcus aureus and two with P aeruginosa. Attempts to eradicate these bacteria from these three patients were unsuccessful. They experienced more than one exacerbation during the study period and exhibited increased production of purulent sputum. Patients with an exacerbation and negative cultures were treated empirically with antibiotics according to the results of previous studies (13). Long-term antibiotic regimens were prescribed in the present study (14). 
TABLE 1

Summary and comparison of inflammation markers recorded during the bronchiectasis study

\begin{tabular}{|c|c|c|c|c|c|c|}
\hline \multirow[b]{2}{*}{ Parameter } & \multicolumn{3}{|c|}{ Stable condition } & \multicolumn{3}{|c|}{ Exacerbation } \\
\hline & Total & Men & Women & Total & Men & Women \\
\hline$\overline{\mathrm{CRP}}, \mathrm{mg} / \mathrm{L}$ & $6.2(0.0-24.0)$ & $5.0(0.0-18.0)$ & $7.3(0.0-24.0)$ & $62.5(10.0-141.0)$ & $44.6(14.0-70.0)$ & $67.3(10.0-141.0)$ \\
\hline WBC, $\times 10^{9} / \mathrm{L}$ & $7.136(3.990-12.920)$ & $7.207(3.990-12.450)$ & $7.082(4.550-12.920)$ & $8.301(4.870-12.580)$ & $7.522(4.870-10.900)$ & $8.585(6.310-12.580)$ \\
\hline \multicolumn{4}{|l|}{ CRP, mg/L } & $<0.0001$ & 5.62 & $42.32-70.08$ \\
\hline \multicolumn{4}{|l|}{ WBC, $\times 10^{9} / \mathrm{L}$} & 0.098 & 1.165 & $-0.227-2.558$ \\
\hline
\end{tabular}

Data presented as mean (range). CRP C-reactive protein; WBC White blood cells

TABLE 2

Characteristics of the four patients from whom respiratory syncytial virus (RSV) RNA was detected in bronchoalveolar lavage (BAL) samples during the baseline visit

\begin{tabular}{lcccc}
\hline & \multicolumn{4}{c}{ Patient } \\
\cline { 2 - 5 } & $\mathbf{1}$ & $\mathbf{2}$ & $\mathbf{3}$ & $\mathbf{4}$ \\
\hline Visit category & Baseline & Baseline & Baseline & Baseline \\
BAL RSV PCR & Positive & Positive & Positive & Positive \\
Serum RSV IgM & Negative & Negative & Negative & Negative \\
Serum RSV IgG* & Twofold & Twofold & Stable & Twofold \\
& increase & increase & & decrease \\
Month of visit & September & June & August & November \\
Baseline FEV, L $(\%)^{\dagger}$ & $1.37(33)$ & $1.16(62)$ & $1.5(63)$ & $3.84(82)$ \\
Baseline symptoms & Cough & Cough & None & Cough \\
& Dyspnea & Dyspnea & None & - \\
White blood cells, $\times 10^{9} / \mathrm{L}$ & 7.050 & 6.420 & 5.640 & 8.690 \\
C-reactive protein, $\mathrm{mg} / \mathrm{L}$ & 5 & 10 & 4 & 2 \\
\hline
\end{tabular}

${ }^{*}$ Three weeks after initial measurement; ${ }^{\dagger}$ Percentage of the mean predicted value. FEV 1 Forced expiratory volume in $1 \mathrm{~s} ; \mathrm{Ig}$ Immunoglobulin; PCR Polymerase chain reaction

Applying univariate logistic regression models, the only parameter associated with exacerbation was the isolation of a culprit bacterium. Finally, patients with baseline colonization did not experience more exacerbations compared with those who were not colonized (Table 4).

\section{DISCUSSION}

To our knowledge, the present study was the first to investigate the role of viruses and atypical bacteria in non-CF bronchiectasis using PCR in BAL samples. These data are missing from large collaborative networks and guidelines regarding bronchiectasis.

The small size of the cohort and the low exacerbation rate were the main limitations. This reduced the probability of isolating culprit microorganisms. The small size of the cohort reduced the power of the study and, thus, the ability to confirm the results. Small cohort size is one of the limitations of single-centre studies. The cohort size was further reduced because of the strict protocol. Some patients with clinical suspicion of bronchiectasis were not referred to the study team because their diagnosis was not confirmed using HRCT. The protocol also required the ability to undergo bronchoscopy and to maintain a personal calendar - requirements that were not met by 13 patients who were initially screened for study entry. Furthermore, the results from four patients (almost 10\% of the cohort) were not included in the final analysis because of missing data. All of these limitations derived from the strict protocol reduced the cohort size by almost one-half. In addition to the small cohort size, the exacerbation rate per patient per year in our study was only 0.58 , one of the lowest reported in the literature (14). This could be partly attributed to the continuous monitoring of the patients in the study group. As a final point, some patients with mild exacerbation may have been misclassified in stable condition because the clinical criteria of an exacerbation are subjective.

The microbiological status of the patients in our study did not differ from previous studies investigating non-CF bronchiectasis during
TABLE 3

Bacteria isolated from bronchoscopy samples during an observational study in patients with non-cystic fibrosis bronchiectasis

\begin{tabular}{lccc}
\hline & \multicolumn{2}{c}{ Presenting condition } & \\
\cline { 2 - 3 } Bacteria & Stable & Exacerbation & Total \\
\hline Pseudomonas aeruginosa & $8(6)$ & $5(5)$ & $13(11)$ \\
Staphylococcus aureus & $5(4)$ & $3(3)$ & $8(7)$ \\
Haemophilus influenzae & $3(3)$ & $4(4)$ & $7(7)$ \\
Streptococcus pneumoniae & $1(1)$ & $2(2)$ & $3(3)$ \\
Proteus mirabilis & 1 & 1 & 2 \\
Klebsiella pneumoniae & 1 & 1 & 2 \\
Enterobacter aerogenes & 1 & - & 1 \\
Serratia rubidaea & 1 & - & 1 \\
Enterobacter cloacae & 1 & - & 1 \\
Candida albicans & 1 & - & 1 \\
\hline
\end{tabular}

Data presented as unique patients, $n$ (number of different patients from whom a microorganism was isolated)

baseline $(2,10,15)$ and exacerbation periods (13). This is also an important result because the present study was performed in a country with increased antibiotic resistance. Again, we verified that a positive culture was strongly correlated with an exacerbation.

The attribution of $\mathrm{M}$ pneumoniae as causative agent of bronchiectasis has been previously reported $(16,17)$. We did not find any data regarding baseline colonization from atypical bacteria or their role in exacerbations. However, there are data from other obstructive lung diseases. The role of viruses and atypical bacteria has been investigated in chronic obstructive pulmonary disease (COPD) exacerbations (18). Atypical bacteria have also been investigated among CF patients $(19,20)$, although few studies used molecular techniques $(21,22)$. Noteworthy, the investigators who studied the role of viruses using molecular techniques used nasal secretions - either exclusively or in conjunction - with sputum samples $(18,22)$. Samples from the upper respiratory tract were also used by investigators who studied atypical bacteria in studies not related to bronchiectasis $(9,18)$. Consequently, the use of BAL samples in our study, and not nasal or sputum samples, combined with the fact that we were not looking for upper respiratory viruses, may have contributed to these low isolation figures. Nevertheless, our results regarding atypical bacteria appear to be consistent with the aforementioned studies, although performed in different disease groups; however, extrapolation of these results should be done with caution (23). For example, in 66 exacerbations recorded from 83 COPD patients, Seemungal et al (18) reported only one positive sample for $\mathrm{C}$ pneumoniae and none for $\mathrm{M}$ pneumoniae. This was also the case for Emre et al (20), who reported only negative results when investigating the role of $\mathrm{M}$ pneumoniae in CF patients.

The role of RSV has previously been investigated in COPD and CF, but we could not find any studies examining non-CF bronchiectasis. Isolation of RSV RNA in COPD patients is usually associated with symptomatic infections, but it was also detected in stable patients $(8,18)$. This was characterized as a low-grade asymptomatic infection and has been associated with disease severity in stable COPD (18). 


\section{TABLE 4 \\ Parameters associated with bronchiectasis exacerbations during an observational study in patients with non-cystic fibrosis bronchiectasis}

\begin{tabular}{lcc}
\hline Parameter & & P (Fisher's exact test) \\
\hline $\begin{array}{l}\text { Bacterial colonization } \\
\text { Logistic regression analysis }\end{array}$ & & 0.071 \\
\hline Parameter & $\mathbf{P}$ & OR (95\% Cl) \\
\hline Positive culture (any bacteria) & 0.012 & $7.78(1.56-38.75)$ \\
\hline
\end{tabular}

Possible explanations given for the detection of RSV RNA in stable COPD patients were laboratory contamination, aborted infection and low-grade asymptomatic infection (8). In our study, the four positive isolations of RSV RNA were in patients in a clinically stable situation and negative for IgM antibodies during their first baseline visit. The nondiagnostic change in RSV IgG titres, in three of these four patients, may indicate a recent past RSV infection (24). As mentioned, two of these patients were checked again in an exacerbation and, again, RSV RNA was not isolated. Future studies investigating viruses in bronchiectasis should examine both the upper and lower respiratory tract. Additionally, the sampling method (eg, nasal swab or BAL) should be standardized because sampling method appears to be important (25).

\section{CONCLUSION}

We did not confirm an association between bronchiectasis exacerbations and atypical bacteria or RSV, although our results were derived from a small cohort. If our results are validated in larger studies, treatment of bronchiectasis exacerbations should be focused solely on already known culprits, the common bacteria.

DISCLOSURES: The authors have no financial disclosures or conflicts of interest to declare.

\section{REFERENCES}

1. Cole PJ. Inflammation: A two-edged sword - the model of bronchiectasis. Eur J Respir Dis Suppl 1986;147:6-15.

2. Angrill J, Agustí C, Celis R, et al. Bacterial colonisation in patients with bronchiectasis: Microbiological pattern and risk factors. Thorax 2002;57:15-9.

3. Martínez-García MA, Soler-Cataluña JJ, Perpiñá-Tordera M, Román-Sánchez P, Soriano J. Factors associated with lung function decline in adult patients with stable non-cystic fibrosis bronchiectasis. Chest 2007;132:1565-72.

4. Nicotra MB, Rivera M, Dale AM, Shepherd R, Carter R. Clinical, pathophysiologic, and microbiologic characterization of bronchiectasis in an aging cohort. Chest 1995;108:955-61.

5. Barker AF. Bronchiectasis. N Engl J Med 2002;346:1383-93.

6. Pasteur MC, Bilton D, Hill AT. British Thoracic Society guideline for non-CF bronchiectasis. Thorax 2010;(65 Suppl 1):i1-58.

7. Esposito S, Blasi F, Bellini F, Allegra L, Principi N. Mycoplasma pneumoniae and Chlamydia pneumoniae infections in children with pneumonia. Eur Respir J 2001;17:241-5.

8. Falsey AR, Formica MA, Hennessey PA, Criddle MM, Sullender WM, Walsh EE. Detection of respiratory syncytial virus in adults with chronic obstructive pulmonary disease. Am J Respir Crit Care Med 2006;173:639-43

9. Almasri M, Diza E, Papa A, Eboriadou M, Souliou E. Mycoplasma pneumoniae respiratory tract infections among Greek children. Hippokratia 2011;15:147-152.

10. Cabello H, Torres A, Celis R, et al. Bacterial colonization of distal airways in healthy subjects and chronic lung disease: A bronchoscopic study. Eur Respir J 1997;10:1137-44.
AUTHOR CONTRIBUTIONS: Dr Metaxas: contributed to patient enrollment, design of the study, conception of the experiments, analysis and interpretation of the data, drafting of the manuscript and approval of the final version. Dr Balis: contributed to the conception and design of the study, patient enrollment, conception of the experiments, analysis and interpretation of the data, review of the report and approval of the final version. Dr Papaparaskevas: contributed to conception of the experiments, analysis and interpretation of the data, review of the report and approval of the final version. Dr Spanakis: contributed to the conception of the experiments, review of the report and approval of the final version. Dr Tatsis: contributed to patient enrollment, review of the report and approval of the final version. Dr Tsakris: contributed to the conception of the experiments, design of the study, interpretation of the data, review of the report and approval of the final version.

OTHER CONTRIBUTIONS: The authors are grateful to all patients agreeing to participate in thier study. They gratefully acknowledge Dr D Chrysovergi for her invaluable help in patient enrollment.

11. Nadal D, Bossart W, Zucol F, et al. Community-acquired pneumonia in children due to Mycoplasma pneumoniae: Diagnostic performance of a seminested 16S rDNA-PCR. Diagn Microbiol Infect Dis 2001;39:15-9.

12. Tong CY, Sillis M. Detection of Chlamydia pneumoniae and Chlamydia psittaci in sputum samples by PCR. J Clin Pathol 1993;46:313-7.

13. Murray MP, Turnbull K, Macquarrie S, Hill AT. Assessing response to treatment of exacerbations of bronchiectasis in adults. Eur Respir J 2009;33:312-8.

14. Wong C, Jayaram L, Karalus N, et al. Azithromycin for prevention of exacerbations in non-cystic fibrosis bronchiectasis (EMBRACE): A randomised, double-blind, placebo-controlled trial. Lancet 2012;380:660-7.

15. Angrill J, Agustí C, De Celis R, et al. Bronchial inflammation and colonization in patients with clinically stable bronchiectasis. Am J Respir Crit Care Med 2001;164:1628.

16. Goudie BM, Kerr MR, Johnson RN. Mycoplasma pneumonia complicated by bronchiectasis. J Infect 1983;7:151-2.

17. Whyte KF, Williams GR. Bronchiectasis after mycoplasma pneumonia. Thorax 1984;39:390-1.

18. Seemungal T, Harper-Owen R, Bhowmik A, et al. Respiratory viruses, symptoms, and inflammatory markers in acute exacerbations and stable chronic obstructive pulmonary disease. Am J Respir Crit Care Med 2001;164:1618-23.

19. Petersen NT, Høiby N, Mordhorst CH, Lind K, Flensborg EW, Bruun B. Respiratory infections in cystic fibrosis patients caused by virus, chlamydia and mycoplasma - possible synergism with Pseudomonas aeruginosa. Acta Paediatr Scand 1981;70:623-8.

20. Emre U, Bernius M, Roblin PM, et al. Chlamydia pneumoniae infection in patients with cystic fibrosis. Clin Infect Dis 1996;22:819-23.

21. Punch G, Syrmis MW, Rose BR, et al. Method for detection of respiratory viruses in the sputa of patients with cystic fibrosis. Eur J Clin Microbiol Infect Dis. 2005;24:54-7.

22. Jones AM, Flight W, Isalska B, et al. Diagnosis of respiratory viral infections in cystic fibrosis by PCR using sputum samples. Eur Respir J 2011;38:1486-7.

23. Athanazio RA, Rached SZ, Rohde C, Pinto RC, Fernandes FL, Stelmach R. Should the bronchiectasis treatment given to cystic fibrosis patients be extrapolated to those with bronchiectasis from other causes? J Bras Pneumol 2010;36:425-4.

24. Hegele RG, Hayashi S, Bramley AM, Hogg JC. Persistence of respiratory syncytial virus genome and protein after acute bronchiolitis in guinea pigs. Chest 1994;105:1848-54.

25. Meerhoff TJ, Houben ML, Coenjaerts FE, et al. Detection of multiple respiratory pathogens during primary respiratory infection: Nasal swab versus nasopharyngeal aspirate using real-time polymerase chain reaction. Eur J Clin Microbiol Infect Dis 2010;29:365-71. 


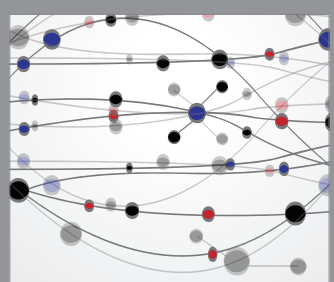

The Scientific World Journal
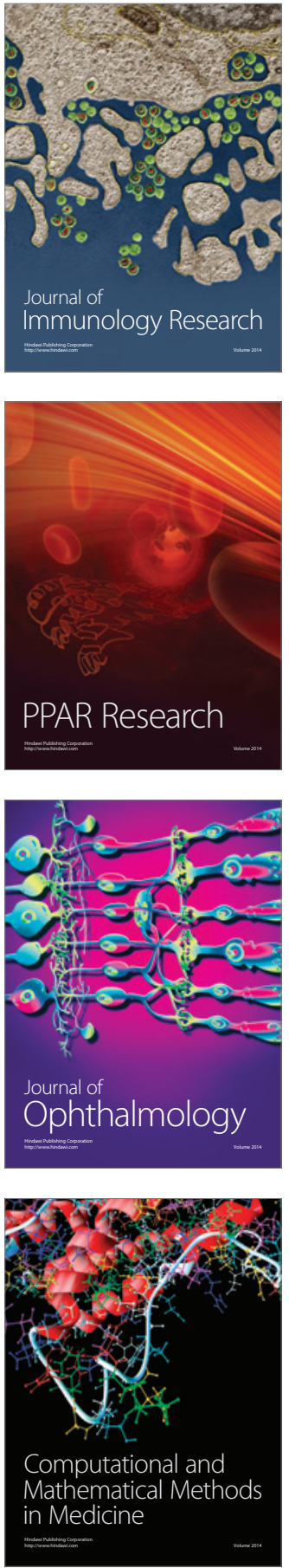

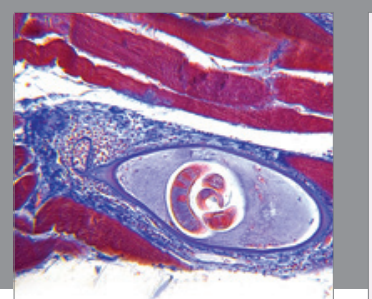

Gastroenterology Research and Practice

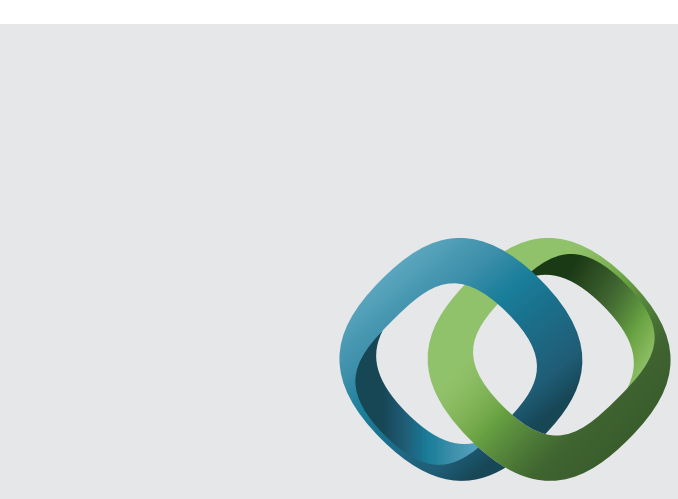

\section{Hindawi}

Submit your manuscripts at

http://www.hindawi.com
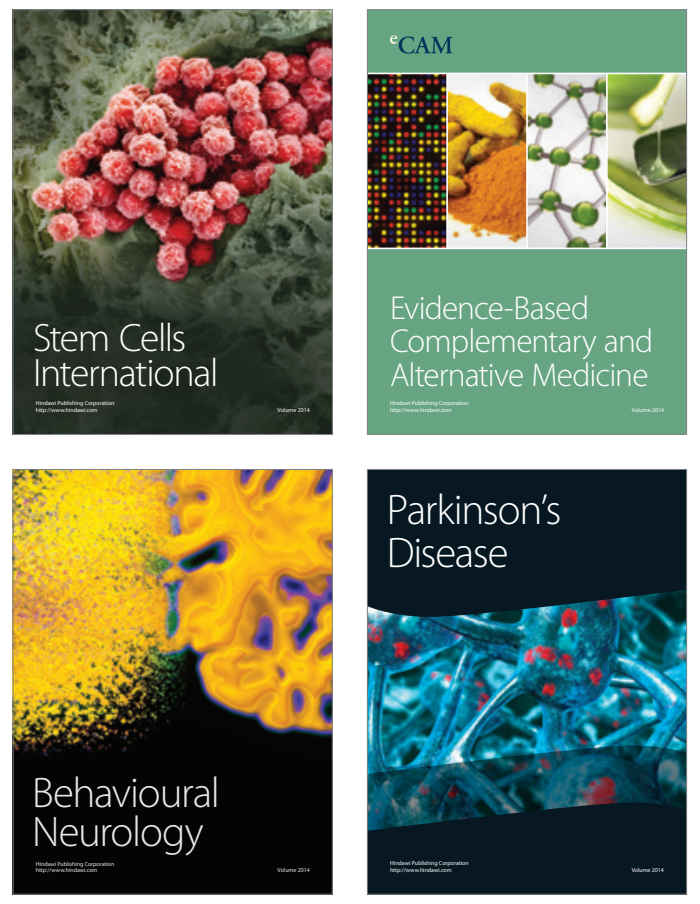
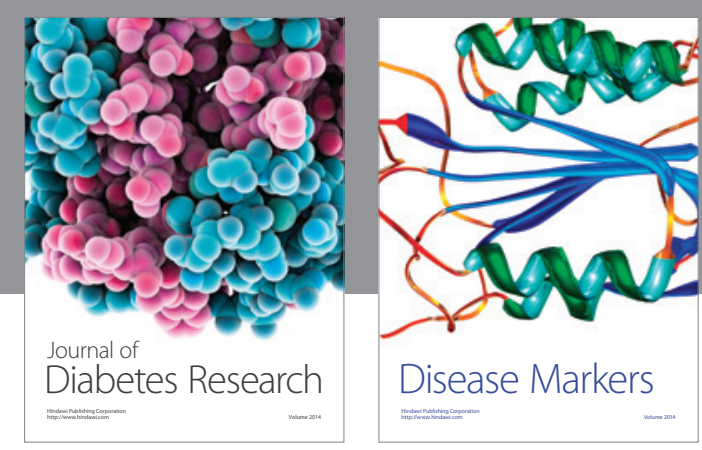

Disease Markers
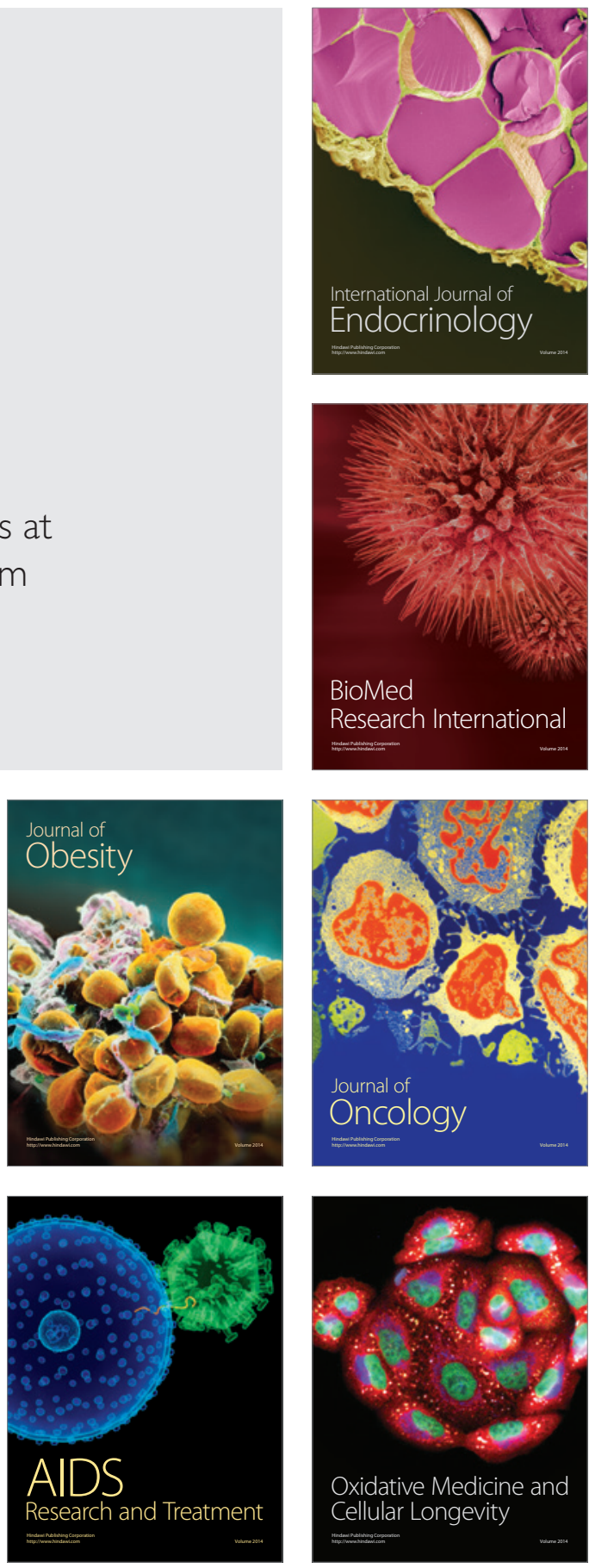